\title{
KEANEKARAGAMAN FAMILI ARTHROPODA TANAH DI KAWASAN HUTAN PENDIDIKAN WANAGAMA KABUPATEN GUNUNGKIDUL DAERAH ISTIMEWA YOGYAKARTA
}

\author{
Muhibbuddin Abdillah ${ }^{1 *}$, Wuri Handayani², Tatag Bagus Putra Prakarsa ${ }^{3}$ \\ 1,2Program Studi Biologi UIN Sunan Ampel Surabaya, Jalan A Yani 117 Surabaya, Indonesia \\ ${ }^{3}$ Program Studi Biologi Universitas Negeri Yogyakarta, Jalan Colombo 01, Sleman, Indonesia \\ *Corresponding author, e-mail: abdillah.kutrik@gmail.com
}

\section{ABSTRACT}

Wanagama Education Forest is the forest made by the ecosystem successions. Wanagama developed on barren hills located at Gunungkidul Province of Yogyakarta Special Region. The succession results providing a new habitat for the wild flora and fauna including soil arthropods. The soil arthropods having an important role in the ecosystem a detritivore etc. This study aimed to knowing soil arthropods diversity at Wanagama. The study conducted at Wanagama Education Forest in December 2017. The soil arthropods collected by six pitch fall trap that was spread at each collection point. Collected specimen by pitch fall trap method then identified and analyzed using diversity, evenness and dominance index. Based on the results, there is 25 family from 13 order of soil arthropods. Based on the data analysis diversity index results are $H^{\prime}=1,53$ and evenness index $E=0$, 47. The dominant individual is from Formicidae that playing a role as predators at Wanagama. Highest diversity is from Coleoptera order.

Keywords: Wanagama, Soil Arthropods, Diversity index

\section{PENDAHULUAN}

Hutan Pendidikan Wanagama merupakan salah satu contoh suksesi hutan hasil rehabilitasi lahan kritis di Indonesia. Wanagama awalnya merupakan bukit gundul yang gersang dan tandus. Fakultas Kehutanan Universitas Gadjah Mada pada tahun 1964 mulai menanam berbagai jenis pohon pada lahan seluas 10 ha. Usaha tersebut membuahkan hasil dan mendapat perhatian serius dari Direktorat Kehutanan sebagai pemilik lahan. Lahan diperluas menjadi 79,9 ha dan diserahkan sepenuhnya kepada Fakultas Kehutanan UGM tahun 1967. Penanaman terus diperluas hingga tertanam lebih dari 169 jenis tumbuhan yang terbagi 9 petak dan 65 blok tanaman pada lahan seluas \pm 600 ha (Anonim, 1988). Keberhasilan dari suksesi tersebut kemudian menyediakan habitat bagi flora dan fauna liar.

Hutan Pendidikan Wanagama merupakan salah satu bentang karst yang masuk dalam Non-Geological Site. Klasifikasi tersebut digunakan untuk kawasan karst dengan geodiversity atau keanekaragaman morfologi bumi yang rendah (Permadi, dkk., 2014). Keberhasilan suksesi di Wanagama menjadi potensi lain dari pemanfaatan bentang karst yang kurang beragam. Flora yang dapat dimanfaatkan hasilnya secara langsung oleh manusia juga menjadi habitat bagi fauna termasuk arthropoda tanah.

Fauna tanah adalah hewan yang hidup di tanah, baik yang hidup di permukaan tanah maupun terdapat di dalam tanah yang merupakan salah satu komponen tanah 
(Suin, 1997). Arthropoda tanah yang merupakan salah satu fauna tanah mempunyai peranan yang sangat penting bagi ekosistem, baik secara langsung maupun tidak langsung. Arthropoda tanah yang dimaksud sebagian besar masuk dalam kelas serangga (insekta). Peranan serangga dalam ekosistem diantaranya adalah sebagai polinator, dekomposer, predator, parasitoid (pengendali hayati), hingga sebagai bioindikator suatu ekosistem (Hakim, dkk., 2011). Arthropoda tanah memiliki peran penting dalam perombakan bahan organik serta berperan penting dalam proses daur ulang unsur hara tanah. Pada ekosistem yang alami tidak tergantung pada manusia, proses dekomposisi akan berlangsung maksimal (Nurhadi \& Widiana, 2010).

Arthropoda tanah berpengaruh dalam karakteristik fisik, kimia, dan biologi tanah (Beare, dkk., 1995). Siklus biogeokimia yang terjadi, dipengaruhi oleh struktur komunitas biotik yang ada di dalam tanah. Menurut Suhardjono (1997), faktor lingkungan seperti suhu udara, suhu tanah, dan $\mathrm{pH}$ tanah sangat memengaruhi keberadaan arthropoda tanah. Beberapa jenis arthropoda yang berada di permukaan tanah dapat digunakan sebagai petunjuk (indikator) terhadap kesuburan atau keadaan tanah terebut. Wanagama sebagai habitat dari arthropoda tanah memiliki hubungan erat yang belum diketahui secara jelas.

Keanekaragaman arthropoda tanah yang tinggi di Indonesia memiliki potensi sebagai indikator kesuburan tanah. Masalah utama dari penggunaan arthropoda sebagai bioindikator adalah kurangnya data dari keanekaragaman arthropoda tanah itu sendiri. Berdasarkan alasan tersebut penelitian bertujuan untuk mempelajari keanekaragaman arthropoda tanah.

\section{METODE}

Studi ini dilakukan di Hutan Pendidikan Wanagama Kabupaten Gunungkidul, Daerah Istimewa Yogyakarta yang dilakukan pada Desember 2017. Pengambilan spesimen arthropoda tanah dilakukan menggunakan metode pitch fall trap yang disebar pada 10 titik di Wanagama. Pitch fall trap dibiarkan selama 24 jam kemudian spesimen disimpan dalam botol tertutup. Spesimen yang telah dikoleksi kemudian di identifikasi menggunakan panduan dari (Borror, dkk., 1997) sampai pada tingkatan famili. Peta penelitian dapat dilihat pada Gambar 1.

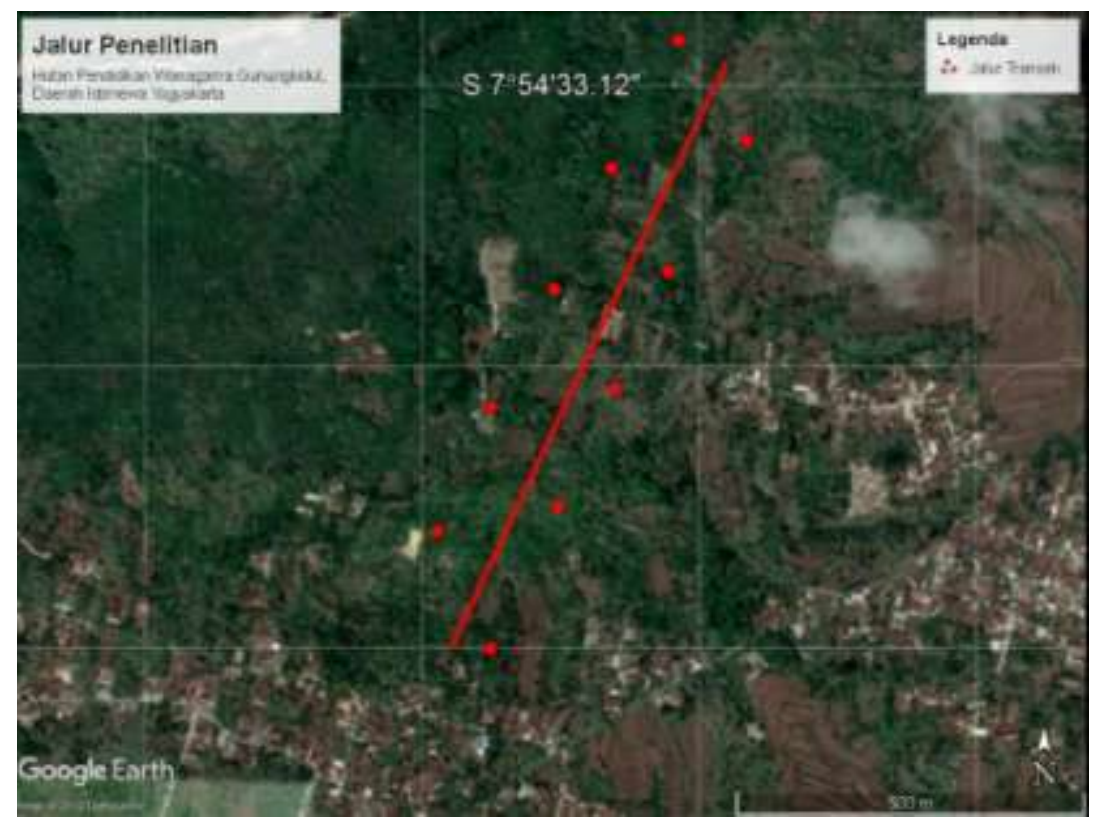

Gambar 1. Peta Lokasi Penelitian (Google Earth) 
Data jumlah individu dan famili yang diperoleh kemudian di analisis menggunakan indeks Diversitas Shannon-Wiener. Selain itu, dilakukan juga analisis indeks kemerataan dan dominansi famili arthropoda tanah.

Analisis indeks Diversitas Shannon-Wiener dilakukan menggunakan rumus sebagai berikut (Hill, dkk., 2005):

$$
\begin{aligned}
& H^{\prime}=-\sum_{\mathrm{i}=1}^{\mathrm{n}}\left(\frac{n i}{N} \ln \frac{n i}{N}\right) \\
& \text { Keterangan: } \\
& H^{\prime} \quad=\text { Indeks Diversitas } \\
& n i \quad=\text { Jumlah Individu (n) } \\
& N \quad=\text { Jumlah Keseluruhan Individu }
\end{aligned}
$$

Analisis indeks kemerataan (Index of Evenness) menggunakan rumus sebagai berikut (Magguran, 1988):

$$
\begin{aligned}
& E=H^{\prime} / \ln S \\
\text { Keterangan : } & \\
E & =\text { Indeks Kemerataan } \\
H^{\prime} & =\text { Indeks Diversitas } \\
S \quad & =\text { Jumlah Jenis }
\end{aligned}
$$

Analisis indeks dominansi (Index of Dominance) menggunakan rumus sebagai berikut (Magguran, 1988):

$$
D=\sum\left(\frac{n i}{N}\right)^{2}
$$

$$
\begin{array}{ll}
\text { Keterangan : } \\
D \quad=\text { Indeks Dominansi } \\
n i \quad=\text { Jumlah Individu (n) } \\
N \quad \text { = Jumlah Keseluruhan Individu }
\end{array}
$$

\section{HASIL DAN PEMBAHASAN}

Hasil identifikasi menunjukkan bahwa ada 25 famili yang diperoleh dari Wanagama dan beberapa famili dengan jumlah individu yang sangat banyak tetapi lainnya hanya ditemukan satu individu. Famili dengan jumlah individu paling banyak adalah Formicidae dengan jumlah 149 individu. Termitidae, Carabidae, Chrysomelidae, Cicindellidae, Coccinellidae, Lygaeidae, Curculionidae, Blatellidae, Antodiaetidae, Forficulidae, Scorpiones, Opiliones, Myriapoda hanya ditemukan satu individu.

Formicidae yang ditemukan dalam jumlah individu paling banyak merupakan famili yang meliputi semua jenis semut yang sangat penting dalam sebuah ekosistem. Jumlah individu dari Famili Formicidae yang tinggi menunjukkan adanya pendukung baik dari segi habitat dan makanan. Serangga dengan tingkat keanekaragaman yang tinggi ini dikenal sebagai soil enggineer karena dalam pembuatan sarang mereka membuat lubang atau gundukan dari tanah (Siriyah, 2016). Lubang tanah yang dibuat oleh fauna ini memungkinkan terjadinya pertukaran udara yang digunakan bakteri tanah dalam mendekomposisi bahan-bahan organik. Bahan tersebut kemudian berfungsi sebagai sumber hara bagi vegetasi di hutan (Amir, dkk., 2003). Formicidae dalam ekosistem juga berperan penting sebagai predator. Oecopilla smaragdina dari 
Famili Formicidae terbukti secara signifikan menurunkan populasi beberapa jenis hama pada Anacardium occidentale L. di Australia (Peng \& Christian, 2010).

Coleoptera adalah salah satu ordo pada Kelas Insekta dengan keanekaragaman yang tinggi dan melimpah. Hasil penelitian juga mendukung bahwa Coleoptera memiliki keanekaragaman yang tinggi karena memiliki famili paling banyak daripada ordo lainnya. Coleoptera atau yang umum disebut kumbang memiliki peranan yang penting dalam ekosistem (Schowalter, 2011). Peranan Coleoptera dalam ekosistem sangat beraneka ragam mulai dari predator seperti Carabidae, Cicindellidae, Coccinellidae (Rahayu, dkk., 2017), hama seperti Chrysomelidae (Dinawirka, dkk., 2014) dan herbivora seperti Curculionidae (Rahayu, dkk., 2017). Berdasarkan pernyataan tersebut, Wanagama memiliki Coleoptera dengan keanekaragaman yang banyak dan mengindikasikan keberhasilan suksesi tersebut.

Tabel 1. Data Hasil Identifikasi

\begin{tabular}{|c|c|c|}
\hline Ordo & Famili & Total \\
\hline Hymenoptera & Formicidae & 149 \\
\hline \multirow[t]{2}{*}{ Isoptera } & Rhinothermitidae & 2 \\
\hline & Termitidae & 1 \\
\hline \multirow[t]{9}{*}{ Coleoptera } & Carabidae & 1 \\
\hline & Chrysomelidae & 1 \\
\hline & Cicindellidae & 1 \\
\hline & Coccinellidae & 2 \\
\hline & Curculionidae & 1 \\
\hline & Lygaeidae & 1 \\
\hline & Platypodidae & 8 \\
\hline & Sphaeriidae & 8 \\
\hline & Staphinilidae & 6 \\
\hline Blattaria & Blattellidae & 1 \\
\hline \multirow[t]{2}{*}{ Orthoptera } & Gryllidae & 2 \\
\hline & Tridactylidae & 11 \\
\hline Diptera & Tipulidae & 2 \\
\hline Entomobryomorpha & Entomobridae & 5 \\
\hline \multirow[t]{2}{*}{ Araneae } & Antrodiaetidae & 1 \\
\hline & Dipluridae & 4 \\
\hline \multirow[t]{2}{*}{ Dermaptera } & Forficulidae & 1 \\
\hline & Labiidae & 6 \\
\hline IsopodaC & - & 3 \\
\hline Scorpiones $^{\mathrm{C}}$ & - & 1 \\
\hline Opiliones ${ }^{0}$ & - & 1 \\
\hline Myriapodac & - & 1 \\
\hline \multicolumn{2}{|c|}{ Total } & 220 \\
\hline
\end{tabular}

Analisis indeks Diversitas Shannon-Wiener menunjukkan bahwa nilai keanekaragaman arthropoda tanah di Wanagama adalah $H^{\prime}=1$,53. Ekosistem dapat dibandingkan tingkat stabilitasnya menggunakan hasil analisis indeks Diversitas. Berdasarkan hasil analisis tersebut tingkat kestabilan ekosistem di Wanagama lebih tinggi jika dibandingkan ekosistem di hutan homogen dan heterogen Arboretum dan Kampus Universitas Lancang Kuning (UNILAK) yaitu $H^{\prime}=1,17$ dan $H^{\prime}=1,15$ (Sari, 2014). Nilai Diversitas yang tinggi menunjukkan keberhasilan dari suksesi hutan Wanagama. 
Analisis indeks kemerataan (Evennes Index) menunjukkan bahwa nilai kemerataan famili arthropoda tanah di Wanagama Wanagama adalah $E=0,47$. Nilai indeks kemerataan biasanya muncul antara $E=0-1$ semakin tinggi nilai indeks kemerataan maka dapat diartikan bahwa persebaran taksa dan individu semakin merata (Krebs, 1989). Kemerataan jumlah individu pada setiap taksa di Wanagama menunjukkan bahwa hutan menyediakan makanan bagi arthropoda dengan cukup merata.

Analisis indeks dominansi Simpson menunjukkan bahwa nilai dominansi famili arthropoda tanah di Wanagama adalah $D=0,46$. Dominansi digunakan untuk mengetahui besar peran suatu taksa dalam komunitas. Nilai $D=0,46$ merupakan nilai yang cukup besar dan menunjukkan jika arthropoda tanah di Wanagama memiliki peranan ekologis yang penting dalam komunitas makhluk hidup di Wanagama (Magguran, 1988).

\section{SIMPULAN}

Keanekaragaman arthropoda tanah di Hutan Pendidikan Wanagama memiliki nilai indeks Diversitas Shannon-Wiener $H^{\prime}=1,53$. Kemerataan arthropoda tanah di Hutan Pendidikan memiliki nilai $E=0,47$. Perolehan data arthropoda tanah sebanyak 25 famili dengan peran ekologis yang berbeda-beda. Berdasarkan hasil identifikasi Famili Formicidae yang memiliki peran utama sebagai predator dalam ekosistem ditemukan dalam jumlah individu tertinggi yaitu 149.

\section{UCAPAN TERIMAKASIH}

Terima kasih kepada Mahasiswa Biologi UIN Sunan Ampel Angkatan 2016 dan Asisten Sistematika Hewan untuk semester genap tahun 2018 sebagai pengambil sampel dalam penelitian ini. Terimakasih kepada Program Studi Biologi UIN Sunan Ampel yang telah mengadakan program PPL 2018 dan telah memberikan izin untuk penggunaan alat untuk keperluan Identifikasi. Terimakasih juga untuk Kelompok Studi Entomologi KUTRIK yang telah banyak membantu menyelesaikan penelitian ini.

\section{REFERENSI}

Amir, M., Noerdjito, W. A., \& Kahono, S. (2003). Serangga Taman Nasional Gunung Halimun Jawa Bagian Barat. Biodiversity Concervation Project. Jakarta.

Anonim. (1988). Master Plan Wanagama Sebagai Pendukung Pembangunan Hutan Tanaman Industri. Departemen Kehutanan RI dan Fakultas Kehutanan UGM, Yogyakarta

Beare, M. H., Coleman, D. C., Crossley, D. A., Hendrix, P. F., \& Odum, E. P. (1995). A hierarchical approach to evaluating the significance of soil biodiversity to biogeochemical cycling. Plant and Soil. 170 (1): 5-22.

Borror, D. J., C. A. Triplehorn \& N. F. Johnson. (1997). Pengenalan Pelajaran Serangga. Yogyakarta: Gadjah Mada University Press.

Dinarwika, P., Himawan, T., \& Tarno, H. (2014). Identifikasi Morfologi Phyllotreta spp.(Coleoptera: Chrysomelidae) pada Tanaman Sayuran di Trawas, Mojokerto. Jurnal Hama dan Penyakit Tumbuhan, 2(2): 47-57.

Hakim, L., Retnaningdyah, C., Sunaryo \& Yanuwiadi, B. (2011). Project on Capacity Building for Restoration of Ecosystems in Conservation Areas: Basic Survey for Ranu Pani-Ranu Regulo Restoration Project. JICA-Minitry of Forestry-Dept.of Biology Brawijaya University-Bromo Tengger Semeru National Park. Malang, East Java 
Hill, D., Fasham, M., Tucker, G., Shewry, M., \& Shaw, P. (Eds.). (2005). Handbook of Biodiversity Methods: Survey, Evaluation and Monitoring. Cambridge: Cambridge University Press.

Krebs, C. J. (1989). Ecological Methodology (No. QH541. 15. S72. K74 1999.). New York: Harper \& Row.

Magurran, A. E. (1988). Ecological Diversity and Its Measurement. New Jersey: Princeton University Press.

Nurhadi, N. \& Widiana, R. (2010). Komposisi Arthropoda Permukaan Tanah Di Kawasan Penambangan Batubara Di Kecamatan Talawi Sawahlunto. Sainstek: Jurnal Sains dan Teknologi, 2(1), 34-39.

Paoletti, M.G. (1999). Using Bioindicators Based on Biodiversity to Asses Landscape Sustainability. Agriculture, Ecosystem and Environment, 74 (1-3): 1-18 doi.org/10.1016/S0167-8809(99)00027-4

Peng, R. \& Christian, K. (2010). Ants As Biological-control Agents In The Horticultural Industry in Lach, L., Parr, C.L., \& Abbott, K.L.(editor) Ant Ecology. Oxford University Pers. 123-125.

Permadi, R., Rachwibowo, P., \& Hidajat, W. K. (2014). Potensi Situs-Situs Warisan Geologi di Area Kars Gunung Sewu sebagai Pendukung dan Peluang Pengembangan Geopark di Indonesia untuk Aset Geowisata Kreatif. Geological Engineering EJournal, 6(2): 586-601.

Rahayu, G. A., Buchori, D., Hindayana, D., \& Rizali, A. (2017). Keanekaragaman dan Peran Fungsional Serangga Ordo Coleoptera di Area Reklamasi Pascatambang Batubara di Berau, Kalimantan Timur. Jurnal Entomologi Indonesia, 14(2): 97-106. doi:5994/jei.14.2.97

Rahmawaty. (2004). Studi Keanekaragaman Mesofauna Tanah Di Kawasan Hutan Wisata Alam Sibolangit. (Skripsi). Sumatera Utara: Jurusan Kehutanan Fakultas Pertanian Universitas Sumatera Utara

Sari, M. (2014). Identifikasi Serangga Dekomposer di Permukaan Tanah Hutan Tropis Dataran Rendah (Studi Kasus di Arboretum dan Komplek Kampus UNILAK dengan Luas 9, 2 Ha). Bio Lectura, 2(1): 63-72.

Schowalter, T. (2011). Insect ecology: an ecosystem approach. United States: Academic Press.

Siriyah, S. L. (2016). Keanekaragaman dan Dominansi Jenis Semut (Formicidae) di Hutan Musim Taman Nasional Baluran Jawa Timur. Journal Biota, 1(2):85-90. doi:10.24002/biota.v1i2.995

Suhardjono, Y. R., \& Adisoemarto, S. (1997). Arthropoda Tanah dan Artinya bagi Tanah. Makalah dalam Kongres dan Simposium Entomologi V, Bandung, 24-26.

Suin, N. M. (1997). Ekologi Hewan Tanah. Jakarta : Penerbit Bumi Aksara. 